\title{
OSAHS
}

\section{Nasal pathologies in patients with obstructive sleep apnoea}

\author{
Patologie nasali in pazienti affetti da sindrome delle apnee ostruttive del sonno

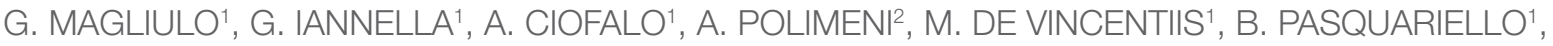 \\ F. MONTEVECCHI ${ }^{3}, \mathrm{C} . \mathrm{VICINI}^{3}$ \\ ${ }^{1}$ Department of "Organi di Senso", University "Sapienza", Rome, Italy; ${ }^{2}$ Department of Oral and Maxillo Facial \\ Sciences, University "Sapienza”, Rome, Italy; ${ }^{3}$ Department of Head-Neck Surgery, Otolaryngology, Head-Neck and \\ Oral Surgery Unit, Morgagni Pierantoni Hospital, Forlì, Italy
}

\begin{abstract}
SUMMARY
Nasal obstruction is a frequent condition in patients with obstructive sleep apnoea (OSA). Nasal obstruction leads to mouth breathing, which is thought to destabilise the upper airway and aggravate the condition. Three conditions could be considered as the cause of the nasal breathing obstruction: anatomical conditions of the nose (septum deviation, hypertrophy of the inferior turbinates), chronic rhinosinusitis (CRS) and chronic nasal inflammation caused by allergic rhinitis or non-allergic cellular rhinitis. In this prospective study, we present an evaluation of all these possible rhino-sinusal aspects in OSA patients to correlate different nasal pathologies with nasal obstruction. Fifty patients with a diagnosis of OSA were enrolled in the study. In $70 \%$ of OSA patients, nasal obstruction was confirmed by clinical evaluation and rhinomanometry testing. Normal rhino-sinus aspects were present in only $20 \%$ of OSA patients, whereas one or more pathological rhino-sinus conditions were present in the remaining $80 \%$. The percentage of OSA patients with a diagnosis of allergic rhinitis and non-allergic rhinitis was $18 \%$ and $26 \%$ respectively. Non-allergic rhinitis with neutrophils (NARNE) was the most frequent type of cellular rhinitis diagnosed in OSA patients (20\% of cases). The results of the present study support and extend the observation that rhinitis is present in OSA patients. Mucosal inflammation caused by these conditions could be the cause of upper airway patency impairment inducing nasal mucosa swelling.
\end{abstract}

KEY WORDS: Obstructive sleep apnoea $\bullet$ Nasal obstruction $\bullet$ Allergic rhinitis $\bullet$ Non-allergic rhinitis $\bullet$ Nasal mucociliary cleareance

\section{RIASSUNTO}

L'ostruzione nasale è una condizione frequentemente riportata in pazienti con sindrome delle apnee ostruttive del sonno (OSAS). L'ostruzione nasale porta alla respirazione orale, che si pensa possa destabilizzare le vie aeree superiori e aggravare l'OSAS. Tre condizioni potrebbero essere considerate come la causa dell'ostruzione respiratoria nasale: condizioni anatomiche nasali (deviazione del setto, ipertrofia dei turbinati inferiori), rinosinusite cronica (CRS) e infiammazione nasale cronica causata da rinite allergica o riniti non allergiche a cellularità. In questo studio prospettico presentiamo una valutazione di tutti questi possibili aspetti naso-sinusali in pazienti con OSAS al fine di correlare le diverse patologie nasali con l'ostruzione respiratoria nasale. Cinquanta pazienti con una diagnosi di OSAS sono stati arruolati nello studio. Nel $70 \%$ dei pazienti con OSAS, l'ostruzione nasale è stata confermata dalla valutazione clinica e dal test della respirazione con rinomanometria. Normali aspetti naso-sinusali erano presenti solo nel $20 \%$ dei pazienti con OSAS, mentre una o più condizioni patologiche naso-sinusali erano presenti nel restante $80 \%$. L'incidenza di pazienti con OSAS con una diagnosi di rinite allergica e rinite non allergica era rispettivamente del 18\% e del 26\%. La rinite non allergica con neutrofili (NARNE) è stata la diagnosi più frequente nei pazienti con OSAS (20\% dei casi). I risultati del presente studio supportano ed estendono l'osservazione che condizioni rinitiche sono presenti nei pazienti con OSAS. L'infiammazione della mucosa causata da queste condizioni potrebbe essere la causa della compromissione delle vie aeree superiori inducendo edema della mucosa nasale.

PAROLE CHIAVE: Sindrome delle apnee ostruttive del sonno $\bullet$ Ostruzione nasale $\bullet$ Riniti allergiche $\bullet$ Riniti non allergiche $\bullet$ Cleareance mucociliare nasale

\section{Introduction}

Obstructive sleep apnoea (OSA) is a clinical entity characterised by recurring episodes of apnoea and/or hypopnoea during sleep due to a total or partial collapse of the upper airway ${ }^{1-3}$. OSA is characterised by night snoring with excessive daytime sleepiness and is commonly associated with a reduced quality of life, cardiovascular diseases, increased healthcare utilisation, motor vehicle accidents and decreased of cognitive performance ${ }^{3-5}$.

Multilevel anatomical obstruction may play a role in OSA ${ }^{3-7}$. Nasal obstruction is frequently reported in these patients ${ }^{5-8}$. Various authors have supported the theory that nasal ob- 
struction is a contributing factor in the pathogenesis of OSA despite numerous controversies ${ }^{6-10}$. Nasal obstruction leads to mouth breathing, which is thought to destabilise the upper airway and aggravate OSA ${ }^{7-9}$. Moreover, nasal breathing obstruction might represent a factor influencing the clinical history of this disease as well as the patient's compliance with CPAP ${ }^{8-11}$.

What is the cause of nasal obstruction in OSA patients? Based on current knowledge about these patients, three conditions could be considered as the cause of the nasal breathing obstruction: anatomical conditions of the nose (septum deviation, hypertrophy of the inferior turbinates), chronic rhinosinusitis (CRS) and, as recently reported, nasal inflammation ${ }^{5-13}$.

The effect of anatomical abnormalities of the nose on the sleep disorders has been analysed by different authors, who confirm an improvement in the number of apnoea/ hypopnoea episodes following surgical correction of nasal abnormalities (septoplasty or turbinoplasty) ${ }^{6-10}$. It has also been well established that CRS causes impaired sleep quality and represents a risk factor for sleep apnoea and daytime sleepiness ${ }^{14}$.

Recently, Zheng et al. ${ }^{16}$ reviewed the literature and suggested a possible correlation between rhinitis and nasal obstruction in OSA patients. Today, it is generally accepted that the chronic nasal inflammation present in allergic and non-allergic rhinitis is a cause of increased nasal airway resistance due to mucosal swelling ${ }^{9-13}$. Therefore, nasal inflammation caused by these conditions may be a factor influencing nasal mucosa swelling and obstruction in OSA patients during sleep ${ }^{10-1316}$. However, these conditions cannot be identified from clinical assessment, nasal symptom scores or rhinomanometry, and need to be studied using specific tests such as the skin prick test and nasal cytology 9-12 17 .

In our opinion, the conditions responsible for nasal obstruction should not be considered separately in OSA patients but rather as a whole, since they may overlap and contribute in different ways to nocturnal nasal obstruction. No study has so far analysed the incidence of these different nasal conditions (AR, NAR, CRS) in OSA patients and their relationship to nasal obstruction. According to the above observations, we designed a prospective study with the subsequent aims: 1) perform an extensive evaluation of all rhino-sinusal aspects in OSA patients; 2) characterise the presence of allergic rhinitis (AR) and non-allergic cellular rhinitis. 3) correlate the different rhino-sinusal pathologies with nasal obstruction.

\section{Materials and methods}

\section{Subjects}

Patients affected by OSA were enrolled in our prospective clinical observational study at the "Organi di Senso" Department of the "Sapienza" University in Rome between December 2014 and January 2018.

Subjects eligible for the study were initially selected from patients referred to our Department with suspected OSA. All these patients underwent polysomnography (PSG) for diagnosis of this pathology. In accordance with the American Academy of Sleep Medicine (AASM), diagnosis and classification of OSA patients were performed on the basis of the apnoea + hypopnoea index (AHI) index. Patients were classified as normal (AHI was $<5 / \mathrm{h}$ ), mild (AHI $\geq 5$ and $<15$ plus typical symptomatology), moderate (AHI $\geq 15$ and $<30$ ) and severe $(\mathrm{AHI} \geq 30)^{18} 19$.

Patients who had undergone surgery to the nose and/or rhino-sinusal surgery were excluded from the study. No patients were undergoing treatment with a CPAP device at home. Patients who were receiving topical or systemic steroids or other nasal therapies were also excluded from the study.

Clinical data, including height and weight, in order to calculate body mass index (BMI), medical history, tobacco use and a list of current medications were initially collected for each patient.

Nasal obstruction and possible presence of the three situations believed to cause OSA (nasal abnormalities, chronic sinusitis, allergic and non allergic cellular rhinitis) were investigated in all patients.

\section{Nasal respiratory obstruction}

The diagnosis of nasal respiratory obstruction was performed by clinical evaluation (self-reported sensation of nocturnal nasal obstruction and dry mouth upon awakening) and a rhinomanometry test. Anterior rhinomanometry is widely used to evaluate nasal resistance. It has been reported in the literature ${ }^{20}$ that the mean total resistance in normal subjects ranges between 0.10 and $0.3 \mathrm{~Pa} / \mathrm{cm}^{3} / \mathrm{s}$, with a mean of $0.25 \mathrm{~Pa} / \mathrm{cm}^{3} / \mathrm{s}$. For this reason, total nasal airway resistance $>0.3 \mathrm{~Pa} / \mathrm{cm}^{3} / \mathrm{s}$ was considered pathological.

\section{Nasal abnormalities}

All patients were submitted to ENT physical examination with nasal endoscopy $\left(2.7 \mathrm{~mm} 0^{\circ}\right.$ rigid endoscope $)$ to evaluate the features of nasal structures (septum deviation, hypertrophy of the inferior turbinates) and detect 
anatomical abnormalities responsible for nasal obstruction.

\section{Chronic rhinosinusitis}

A diagnosis of CRS was made according to the EPOS classification of rhinosinusitis ${ }^{21}$ which considers patients with two or more signs and symptoms (bilateral nasal obstruction, nasal discharge, facial pain/ headache, subjective olfactory dysfunction) for 12 or more weeks, without complete resolution. Any rhinosinusal pathologies (such as nasal polyposis, aspects of chronic rhinosinusitis, nasal infection) were also investigated during nasal endoscopy.

Moreover, all patients underwent CT scan of rhinosinusal structures (axial, coronal and sagittal projections, without the use of intravenous contrast) at the same time as the ENT examination to confirm or exclude CRS.

Allergic and non-allergic cellular rhinitis (AR and NAR) According to ARIA diagnostic criteria ${ }^{22}$ patients with at least 2 of the allergic rhinitis (AR) symptoms were investigated for AR (suggestive symptomatology according to Skin prick test/IgE positivity) and non-allergic cellular rhinitis (NAR). Cellular rhinitis was diagnosed by nasal cytology in patients with a clinical suggestive history of $\mathrm{AR}$, but without allergic sensitisation (skin prick test/IgE positivity) ${ }^{1122-24}$.

Patients with rhinopathy were subdivided on the basis of the prick test and of nasal cytology into subjects with AR or with NAR ${ }^{1122-24}$. Cellular forms were further sub-divided on the basis of cytotype ${ }^{1124}$.

In accordance with the European Academy of Allergy and Clinical Immunology, standardised allergen panels were employed to detect an IgE-mediated allergic response in all CVID patients ${ }^{22} 23$. The allergen panel consisted of the following: house dust mites (Dermatophagoides farinae and pteronyssinus), cat and dog hair, grasses mix, composite mix, parietaria judaica, birch, hazel tree, olive tree, alternaria tenuis, cladosporium and aspergilli mix; the concentration of allergen extracts was $100 \mathrm{IR} / \mathrm{mL}$ (Stallergenes, Milan, Italy). Sensitisation was considered present when the diameter of local reaction was equal to or greater than $3 \mathrm{~mm}^{22} 23$.

Scrapings of the nasal mucosa were placed on a microscope slide, fixed for air dry and stained by the MayGrunwald-Giemsa method ${ }^{11}{ }^{24}$. The semi-quantitative analysis proposed by Meltzer et al. ${ }^{25}$ was used to evaluate nasal cytology.

According to the semi-quantitative analysis and to the results of skin prick tests, patients were classified as normal or as having AR or NAR ${ }^{1122-25}$. NAR subjects, also defined as cellular rhinitis, were further subdivided into NARNE (neutrophils $>50 \%$ with absent spores and bacteria); NARES (eosinophils > 20\%); NARMA (mast cells $>10 \%$ ); NARESMA (eosinophils $>20 \%$ and mast cells $>10 \%)^{112425}$.

\section{Diagnosis of rhino-sinusal pathologies}

By comparing the results of the above mentioned tests, different conditions were diagnosed: isolated nasal abnormalities, chronic rhinosinusitis (CRS), AR), AR + CRS, NAR and NAR + CRS. Each of these conditions was correlated with the presence of nasal obstruction.

\section{Statistical analysis}

A Student's $T$ test and $\chi^{2}$ test were employed to evaluate the significance of multiple factors. A $p$ value of $<0.05$ was taken as the threshold of statistical significance. This research study was performed in accordance with the principles of the Declaration of Helsinki and approved by the local Ethics Committee of the University "Sapienza" of Rome. All patients gave written informed consent for the PSG, CT scan and other rhinologic tests of the study.

\section{Results}

55 patients with a diagnosis of OSA were enrolled in the study. The mean age of the study group was 55.2 years (range 35-79): 33 subjects were male and 17 were female. The clinical characteristics of the study group are reported in Table I.

In $35(70 \%)$ patients with OSA, nasal obstruction was confirmed by clinical evaluation and rhinomanometry testing (Table I). No difference emerged between OSA subgroups and the incidence of nasal obstruction using the chi square test ( $p>0.5$ in each case). This was confirmed by regression analysis between AHI index and mean nasal airway resistance calculated with the rhinomanometry test $(\mathrm{p}=0.7)$ (Fig. 1).

The diagnostic protocol used in this study showed that normal rhino-sinus aspects were present in only $20 \%$ of OSA patients, whereas one or more pathological rhinosinus conditions were present in the remaining $80 \%$.

The incidence of the different rhino-sinus pathologies present in OSA patients is reported in Table II. Interestingly, the incidence of OSA patients with a diagnosis of AR and NAR was $18 \%$ and $26 \%$, respectively.

In patients with a diagnosis of AR or NAR, mean AHI did not differ from those without rhinitis diagnosis $(p>0.05$ in each case; Fig. 2).

In $82.5 \%$ of patients suffering from a pathological rhinosinus condition, nasal obstruction was present. There was 
Table I. Clinical characteristics of the study group.

$\begin{array}{ll} & \text { OSA patients } \\ & 50 \text { pts } \\ \text { Mean age } & 55.2 \text { years (range 35-79 years old) } \\ & \text { Mild OSA: 54.5 } \\ & \text { Moderate OSA: } 55.1 \\ & \text { Severe OSA: } 57.4 \\ & 33 \text { male } \\ \text { Sex } & 17 \text { female } \\ & 32.5 \\ \text { BMI (mean value) } & \text { Mild OSA } \\ \text { OSA severity } & 15 \text { pts (mean AHI = 10.9) } \\ & \text { Moderate OSA } \\ & 18 \text { pts (mean AHI = 21.5) } \\ & \text { Severe OSA } \\ & 17 \text { pts (mean AHI = 42.6) } \\ & 35 \text { pts } \\ \text { NASAL OBSTRUCTION } & \\ \text { (Clinical evaluation }+ & 10 \text { pts } \\ \text { rinomanometry) } & 11 \text { pts } \\ \text { Mild OSA } & 14 \text { pts } \\ \text { Moderate OSA } & \end{array}$

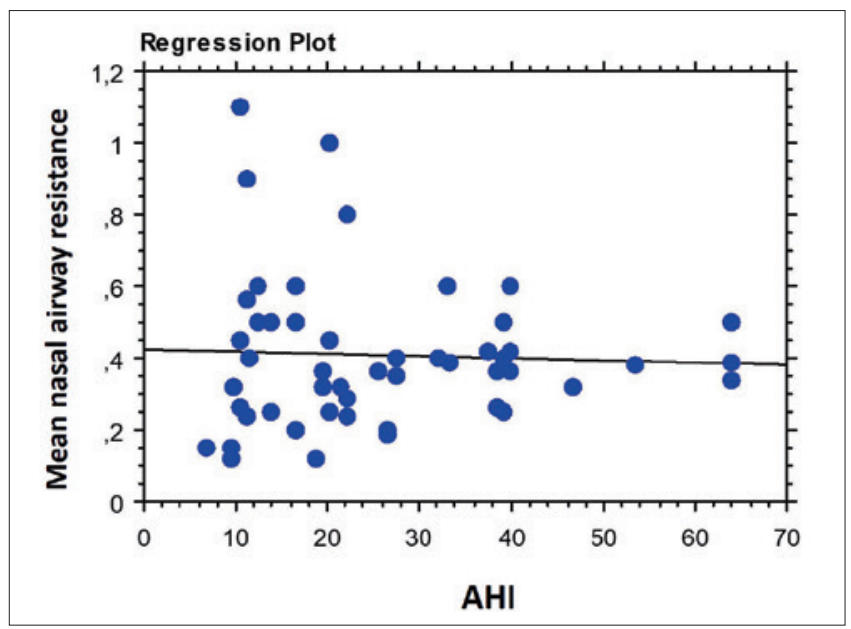

Fig. 1. Regression analysis between $\mathrm{AHI}$ index and mean nasal airway resistance calculated with the rhinomanometry test $(p=0.7)$. a significant difference between normal and pathological subjects regarding nasal obstruction $(\mathrm{p}=0.004)$.

Analysing the different pathological rhino-sinus conditions regarding the simultaneous presence or absence of nasal obstruction, interesting aspects emerged (Table II): 100\% of patients with AR, CRS and AR+CRS showed nasal obstruction, whereas this condition was present in $92.3 \%$ of patients suffering from NAR. Different from these inflammatory conditions, only $60 \%$ of patients with isolated nasal abnormalities (nasal deviation, inferior turbinate hypertrophy etc.) had a diagnosis of nasal obstruction.

Table III displays a subdivision of different pathological rhino-sinus conditions according to Nasal Cytological Outcomes classification. Non-allergic rhinitis with neu-

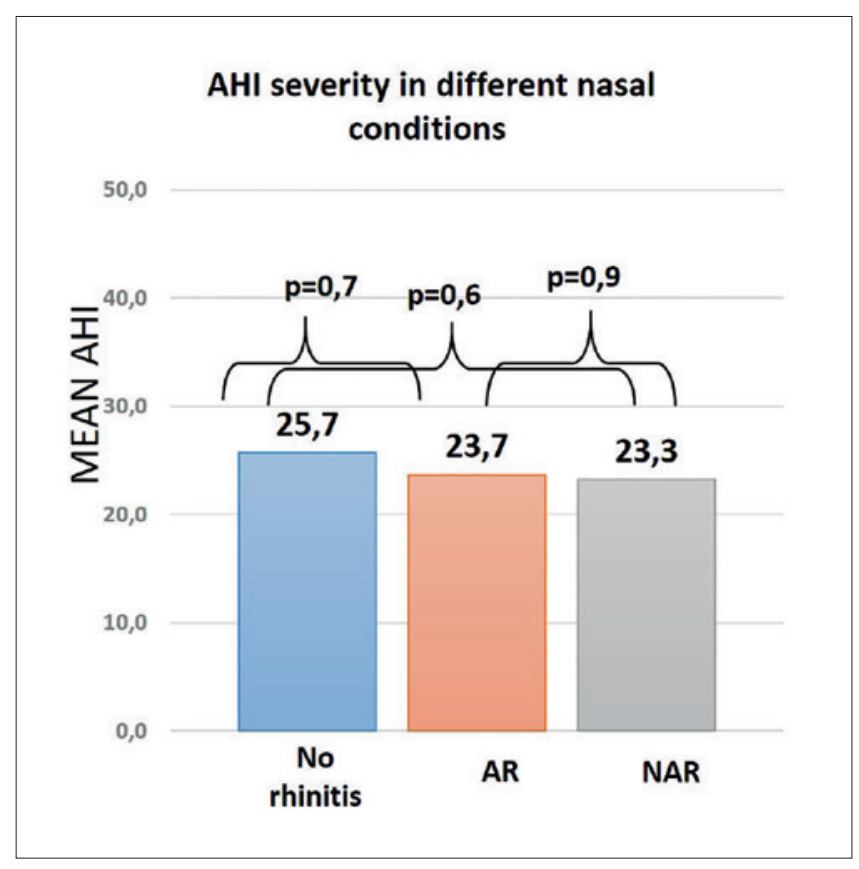

Fig. 2. Mean AHI value of patients without rhinitis and patients with allergic rhinitis and non-allergic rhinitis diagnosis.

Table II. Different rhino-sinusal pathologies present in OSA patients.

\begin{tabular}{lccc} 
& OSA patients & OSA patients with nasal & $\begin{array}{c}\text { OSA patients without nasal } \\
\text { obstruction N (\%) }\end{array}$ \\
obstruction N (\%) & N (\%) & $35(70 \%)$ & $15(30 \%)$ \\
Number of patients & 50 & $2(20 \%)$ & $8(80 \%)$ \\
Pathological rhino-sinusal aspects & $10(20 \%)$ & $33(82.5 \%)$ & $7(15.5 \%)$ \\
Isolated nasal abnormalities & $40(80 \%)$ & $9(60 \%)$ & $6(40 \%)$ \\
(nasal septum deviation, inferior turbinate hypertrophy) & $15(30 \%)$ & $3(100 \%)$ & - \\
Chronic rhinosinusitis (CRS) & $3(6 \%)$ & $4(100 \%)$ & - \\
Allergic rhinitis (AR) & $4(8 \%)$ & $5(100 \%)$ & - \\
CRS + AR & $5(10 \%)$ & $12(92.3 \%)$ & - \\
Non-allergic rhinitis (NAR) & $13(26 \%)$ & - & - \\
NAR + CRS & - & $(7.7 \%)$ & - \\
\hline
\end{tabular}


Table III. Nasal cytological outcomes.

\begin{tabular}{|c|c|c|}
\hline Nasal cytology & Cytological characteristics & Total of patients $\mathrm{N}(\%)$ \\
\hline $\begin{array}{l}\text { Allergic rhinitis } \\
\text { (skin prick test +) }\end{array}$ & Numerous neutrophils and eosinophils, partially degranulated & $9(18 \%)$ \\
\hline $\begin{array}{l}\text { Non allergic cellular rhinitis } \\
\text { NARNE } \\
\text { NARMA } \\
\text { NARES } \\
\text { NARESMA }\end{array}$ & $\begin{array}{l}\text { Neutrophils }>50 \% \text { with absent spores and bacteria } \\
\text { Mast cells }>10 \% \\
\text { Eosinophils }>20 \% \\
\text { Eosinophils }>20 \% \text { and mast cells }>10 \%\end{array}$ & $\begin{array}{c}13(26 \%) \\
10(20 \%) \\
- \\
2(4 \%) \\
1(2 \%)\end{array}$ \\
\hline Infective* & Numerous neutrophils and bacteria & $3(6 \%)$ \\
\hline
\end{tabular}

: patients with cytological characteristics of infective rhinitis was the same with a CRS diagnosis.

trophils (NARNE) was the most frequent NAR diagnosed in OSA patients (20\% of cases). In patients diagnosed with AR, numerous neutrophils and eosinophils, partially degranulated, were evident at cytology, whereas in all those diagnosed with CRS cytological characteristics of infective rhinitis were present.

\section{Discussion}

There is evidence showing that nasal obstruction can contribute to the pathogenesis of OSA, decrease the quality of life in OSA patients, contribute to snoring and represent an obstacle for effective treatment with CPAP ${ }^{6-1126-28}$.

What is the cause of nasal obstruction in OSA patients? A systematic evaluation of nasal obstruction remains challenging due to the high number of factors that contribute to nasal obstruction ${ }^{6810}$. Currently, nasal obstruction evaluation in OSA patients in most medical environments is limited to anterior rhinoscopy: this allows evaluation of anterior septal deviation, internal nasal valve angle and inferior turbinate size, but fails to identify other factors that could play a role in nasal obstruction ${ }^{6-11}$. In addition, characteristics of the anterior nasal cavity frequently do not correlate with the patient's symptoms and/or nasal breathing. Patients often complain of nasal obstruction despite no objective signs of anatomical abnormalities in the nasal cavity when examined with anterior rhinoscopy and/or nasal endoscopy ${ }^{11} 16$.

Other aetiologies for nasal obstruction such as chronic sinusitis or inflammatory problems such as AR and/or nonallergic cellular rhinitis, could be the reason why nocturnal nasal breathing is absent ${ }^{11} 16$.

In our observational study, it emerged that $70 \%$ of OSA patients displayed nasal respiratory obstruction. Normal rhino-sinusal aspects were present in only $20 \%$ of OSA patients examined, whereas one or more pathological rhino-sinusal conditions were present in $80 \%$ of enrolled patients. It is interesting to note that only $30 \%$ of these patients had isolated anatomical abnormalities, $6 \%$ had chronic rhinosinusitis, $18 \%$ AR and $26 \%$ NAR. These corroborate the results reported by Shadan et al. ${ }^{29}$ who employed nasal cytology as a marker of clinically silent inflammation in a group of 38 OSA patients, diagnosing AR in $37 \%$ and NAR in $21 \%$ of subjects.

Regarding the cause of nasal obstruction in OSA patients, it should be noted that $95.4 \%$ of patients with nasal inflammatory conditions such as AR or NAR, suffered from nocturnal respiratory obstruction. In contrast, $40 \%$ of patients with isolated nasal abnormalities did not suffer from nasal obstruction.

Some observational studies have shown how the nasal congestion induced by AR is an important factor in sleep impairment ${ }^{12} 1630$. One large population-based study involving about 5,000 adults demonstrated that individuals reporting frequent nasal congestion (5 nights/month) due to allergy were almost twice as likely to have moderateto-severe SDB than individuals without nasal congestion due to allergy ${ }^{15}$. Moreover, the incidence of AR among patients with OSA was recently estimated to be between $11.7 \%$ and $27.1 \%$ with no significant differences in sleeping parameters between allergic and non-allergic patients ${ }^{10}$.

The mechanism through which AR causes poor quality of sleep and daytime fatigue is not entirely clear, but several factors are believed to be involved. Inflammatory mediators such as interferon- (IFN-) gamma, tumour necrosis factor(TNF-) alpha, interleukin- (IL-) 1b, IL-4, IL-10, postural changes and certain therapeutic agents, such as antihistamines, may have a direct impact on sleep regulation 121316 . However, like AR, non-allergic cellular rhinitis should also be considered among the possible causes of nasal congestion due to inflammation of the mucosa ${ }^{11-13}$.

A high incidence of NAR of $28.7 \%$ in OSA has been recently reported by Zheng et al. ${ }^{12}$ using validated questionnaires and skin prick tests. The patients in this study with NAR had lower average arterial oxygen saturation and minimal arterial oxygen saturation, compared with subjects categorised as no-rhinitis. 
According to the recent ARIA classification, in order to obtain a more precise classification of NAR, nasal cytology tests should be performed in patients with suggestive history of AR, but without allergic sensitisation (Skin prick test/IgE positivity) ${ }^{11} 22-24$.

Using these tests, Gelardi et al. ${ }^{11}$ were the first to demonstrate a subclinical nasal inflammation in patients with OSA in CPAP treatment. They showed that at cytology examination 9 patients (28.1\%) had aspects of NARNE, $6(18.7 \%)$ of NARES and $4(12.5 \%)$ of NARESMA, whereas $5(15.6 \%)$ patients showed cellular signs of AR with numerous neutrophils and eosinophils, partially degranulated: finally in 8 (25\%) patients the cytologic signs of rhinosinusitis characterised by numerous neutrophils and the presence of bacteria. Using the same diagnostic protocol as Gelardi et al. ${ }^{11}$, in our study group of OSA patients NARNE was present in $20 \%$ of cases, whereas NARES and NARESMA was seen in $4 \%$ and $2 \%$, respectively.

Different from other studies, patients with a diagnosis of AR or NAR did not seem to have a mean AHI that was significantly different from that of patients not diagnosed with rhinitis ${ }^{12} 16$ ( $p>0.05$ in all cases). Similar results have been reported by Kramer et al. ${ }^{10}$ who found no significant differences in sleeping behaviour or polysomnography parameters comparing allergic and non-allergic patients. The results of the present study support and extend the observation that rhinitis is present in OSA patients ${ }^{1112} 16$. Mucosa inflammation caused by these conditions may further compromise upper airway patency by inducing nasal mucosa swelling.

In our opinion, inflammatory conditions such as AR and/ or cellular rhinitis should be evaluated in OSA patients to avoid unnecessary surgical procedures, re-establish normal nasal function and improve compliance with eventual CPAP treatment ${ }^{11}$ 29-32. Notwithstanding, further studies are necessary to investigate inflammation mediators in nasal mucosa of OSA patients and correlate these with the presence of nasal obstruction and the severity of OSA.

\section{Conclusions}

One or more pathological rhino-sinusal conditions were present in $80 \%$ of OSA patients evaluated in this study. The incidence of OSA patients with a diagnosis of AR and NAR was $18 \%$ and $26 \%$, respectively. A diagnosis of AR or NAR does not seem to correlate with severity of AHI.

\section{Conflict of interest statement}

None declared.

\section{References}

1 Bosi M, De Vito A, Kotecha B, et al. Phenotyping the pathophysiology of obstructive sleep apnea using polygraphy/polysomnography: a review of the literature. Sleep Breath 2018;22:579-92. https://doi. org/10.1007/s11325-017-1613-3.

2 Paskhover B. An introduction to obstructive sleep apnea. Otolaryngol Clin North Am 2016;49:1303-6. https://doi.org/10.1016/j. otc.2016.07.007.

3 Kapur VK. Obstructive sleep apnea: diagnosis, epidemiology, and economics. Respir Care 2010;55:1155-67.

4 Pinto JA, Ribeiro DK, Cavallini AF, et al. Comorbidities associated with obstructive sleep apnea: a retrospective study. Int Arch Otorhinolaryngol 2016;20:145-50. https://doi. org/10.1055/s-0036-1579546.

5 Schwartz RN, Payne RJ, Forest VI, et al. The relationship between upper airway collapse and the severity of obstructive sleep apnea syndrome: a chart review. J Otolaryngol Head Neck Surg 2015;44:32. https://doi.org/10.1186/s40463-015-0086-2.

6 Migueis DP, Thuler LC, Lemes LN, et al. Systematic review: the influence of nasal obstruction on sleep apnea. Braz J Otorhinolaryngol 2016;82:223-31. https://doi.org/10.1016/j.bjorl.2015.05.018.

7 Alwani A, Rubinstein I. The nose and obstructive sleep apnea. Curr Opin Pulm Med 1998;4:361-2.

8 Vicini C, De Vito A, Benazzo M, et al. The nose oropharynx hypopharynx and larynx (NOHL) classification: a new system of diagnostic standardized examination for OSAHS patients. Eur Arch Otorhinolaryngol 2012;269:1297-300. https://doi.org/10.1007/ s00405-012-1965-z.

9 Georgalas C. The role of the nose in snoring and obstructive sleep apnoea: an update. Eur Arch Otorhinolaryngol 2011;268:1365-73. https://doi.org/10.1007/s00405-010-1469-7.

10 Kramer MF, De La Chaux R, Dreher A, et al. Allergic rhinitis does not constitute a risk factor for obstructive sleep apnea syndrome. Acta Otolaryngol 2001;121:494-9.

11 Gelardi M, Carbonara G, Maffezzoni E, et al. Regular CPAP utilization reduces nasal inflammation assessed by nasal cytology in obstructive sleep apnea syndrome. Sleep Med 2012;13:859-63. https:// doi.org/10.1016/j.sleep.2012.04.004.

12 Zheng M, Wang X, Ge S, et al. Allergic and non-allergic rhinitis are common in obstructive sleep apnea but not associated with disease severity. J Clin Sleep Med 2017;13:959-66. https://doi.org/10.5664/ jcsm.6694.

13 Passali D, Corallo G, Petti A, et al. A comparative study on oxidative stress role in nasal breathing impairment and obstructive sleep apnoea syndrome. Acta Otorhinolaryngol Ital 2016;36:490-5. https:// doi.org/10.14639/0392-100X-1361.

14 Jiang RS, Liang KL, Hsin CH, et al. The impact of chronic rhinosinusitis on sleep-disordered breathing. Rhinology 2016;54:75-9. https://doi.org/10.4193/Rhin15.204.

15 Young T, Finn L, Kim H. Nasal obstruction as a risk factor for sleepdisordered breathing. The University of Wisconsin Sleep and Respiratory Research Group. J Allergy Clin Immunol 1997;99:S757-62.

16 Zheng M, Wang X, Zhang L. Association between allergic and nonallergic rhinitis and obstructive sleep apnea. Curr Opin Allergy Clin Immunol 2018;18:16-25. https://doi.org/10.1097/ ACI.0000000000000414.

17 Passali FM, Bellussi L, Mazzone S, et al. Predictive role of nasal functionality tests in the evaluation of patients before nocturnal polysomnographic recording. Acta Otorhinolaryngol Ital 2011;31:103-8.

18 Berry RB, Brooks R, Charlene E, et al. AASM Manual for the scor- 
ing of sleep and associated events. American Academy of Sleep Medicine; 2015.

19 Epstein LJ, Kristo D, Strollo PJ Jr, et al. Clinical guideline for the evaluation, management and long-term care of obstructive sleep apnea in adults. J Clin Sleep Med 2009;5:263-76.

20 Merkle J, Kohlhas L, Zadoyan G, et al. Rhinomanometric reference intervals for normal total nasal airflow resistance. Rhinology 2014;52:292-9. https://doi.org/10.4193/Rhin13.220.

21 Fokkens WJ, Lund VJ, Mullol J, et al. EPOS 2012: European position paper on rhinosinusitis and nasal polyps 2012. A summary for otorhinolaryngologists. Rhinology 2012;50:1-12. https://doi. org/10.4193/Rhino50E.

22 Brożek JL, Bousquet J, Agache I. Allergic rhinitis and its impact on asthma (ARIA) guidelines-2016 revision. J Allergy Clin Immunol 2017;140:950-8. https://doi.org/10.1016/j.jaci.2017.03.050.

23 Heinzerling L, Mari A, Bergmann $\mathrm{K}$, et al. The skin prick test European standard. Clin Transl Allergy 2013;3:3. https://doi. org/10.1186/2045-7022-3-3.

24 Gelardi M. Atlas of nasal cytology. Milano: Edi Ermes; 2012.

25 Meltzer EO, Orgel HA, Jalowayski AA. Histamine levels and nasal cytology in children with chronic otitis media and rhinitis. Ann Allergy Asthma Immunol 1995;74:406-10.

26 Magliulo G, de Vincentiis M, Iannella G, et al. Olfactory evaluation in obstructive sleep apnoea patients. Acta Otorhinolaryngol Ital 2018;38:338-45. https://doi.org/10.14639/0392-100X-1981.
27 Bican A, Kahraman A, Bora I, et al. What is the efficacy of nasal surgery in patients with obstructive sleep apnea syndrome? J Craniofac Surg 2010;21:1801-6. https://doi.org/10.1097/ SCS.0b013e3181f40551.

28 Magliulo G, de Vincentiis M, Iannella G, et al. Eustachian tube evaluation in patients with obstructive sleep apnea syndrome. Acta Otolaryngol 2018;138:159-64. https://doi.org/10.1080/00016489.2 017.1385846.

29 Shadan FF, Jalowayski AA, Fahrenholz J. Nasal cytology: a marker of clinically silent inflammation in patients with obstructive sleep apnea and a predictor of noncompliance with nasal CPAP therapy. J Clin Sleep Med 2005;1:266-70.

30 Thompson A, Sardana N, Craig TJ. Sleep impairment and daytime sleepiness in patients with allergic rhinitis: the role of congestion and inflammation. Ann Allergy Asthma Immunol 2013;111:446-51. https://doi.org/10.1016/j.anai.2013.05.020.

31 Fiorita A, Scarano E, Mastrapasqua R, et al. Moderate OSAS and turbinate decongestion: surgical efficacy in improving the quality of life and compliance of CPAP using Epworth score and SNOT-20 score. Acta Otorhinolaryngol Ital 2018;38:214-21. https://doi. org/10.14639/0392-100X-1935.

32 Toraldo DM, Passali D, Sanna A, et al. Cost-effectiveness strategies in OSAS management: a short review. Acta Otorhinolaryngol Ital 2017;37:447-53. https://doi.org/10.14639/0392-100X-1520.

Received: April 9, 2018 - Accepted: May 24, 2018

How to cite this article: Magliulo G, Iannella G, Ciofalo A, et al. Nasal pathologies in patients with obstructive sleep apnoea. Acta Otorhinolaryngol Ital 2019;39:250-256. https://doi.org/10.14639/0392-100X-2173

Address for correspondence: Giuseppe Magliulo, Department of “Organi di Senso”, University "Sapienza”, via Gregorio VII 80, 00165 Rome, Italy. E-mail: giuseppemagliuloorl@yahoo.com 